\title{
Titanium Dioxide Nanoparticle and Carbon Nanotube Incorporated Carbon Nanofiber Nanocomposite Modified Electrode for Hemoglobin Electrochemistry
}

\author{
Lin Zhu ${ }^{1,3}$, Yuhua Wang ${ }^{2}$, Zhen Ai $^{3}$, Xi Zhang ${ }^{1}$, Xiaoyan Li $^{1}$, Xiaoping Zhang ${ }^{1,{ }^{*}}$,Wei Sun ${ }^{1, *}$ \\ ${ }^{1}$ Key Laboratory of Water Pollution Treatment and Resource Reuse of Hainan Province, College of \\ Chemistry and Chemical Engineering, Hainan Normal University, Haikou 571158, P. R. China \\ ${ }^{2}$ Shandong Vocational Animal Science and Veterinary College, 261061, Weifang, P. R. China \\ ${ }^{3}$ Key State Laboratory of Industrial Vent Gas Reuse, The Southwest Research \& Design Institute of \\ the Chemical Industry, Chengdu 610225, P. R. China \\ "E-mail: swyy26@ hotmail.com
}

doi: $10.20964 / 2020.05 .85$

Received: 13 Janaury 2020 / Accepted: 3 March 2020 / Published: 10 April 2020

This study aimed to achieve direct electron transfer of bovine hemoglobin $(\mathrm{Hb})$ on titanium dioxide nanoparticle and carbon nanotubes incorporated carbon nanofiber $\left(\mathrm{TiO}_{2}-\mathrm{CNT}-\mathrm{CNF}\right)$ nanocomposite modified carbon ionic liquid electrode (CILE). Electrochemical method was used to check the properties of the modified electrode (Nafion/Hb/TiO $-\mathrm{CNT}-\mathrm{CNF} / \mathrm{CILE}$ ), which confirmed the realization of direct electrochemical reaction with a pair of well-shaped redox peaks on cyclic voltammograms. UV-visible and FT-IR spectra were used to prove the biocompatibility between nanocomposite and $\mathrm{Hb}$ molecules. The study also revealed that $\mathrm{Nafion} / \mathrm{Hb} / \mathrm{TiO}_{2}-\mathrm{CNT}-\mathrm{CNF} / \mathrm{CILE}$ had well electrocatalytic reduction ability to trichloroacetic acid and hydrogen peroxide with good linear relationship between peak current and concentration. Quality analysis of medical sample solution was realized with satisfactory results. The paper demonstrated the potential application of $\mathrm{TiO}_{2}-\mathrm{CNT}-\mathrm{CNF}$ nanocomposite in the field of third generation electrochemical $\mathrm{Hb}$ sensor.

Keywords: Hemoglobin, Direct electrochemistry, Titanium dioxide, Carbon nanofiber, Carbon nanotube

\section{FULL TEXT}

(C) 2020 The Authors. Published by ESG (www.electrochemsci.org). This article is an open access article distributed under the terms and conditions of the Creative Commons Attribution license (http://creativecommons.org/licenses/by/4.0/). 